\title{
THE CANADA LAND INVENTORY OF ARDA
}

\author{
By R. J. MeCORMACK ${ }^{1}$
}

The Canada Land Inventory, the subject of this paper, is being undertaken as a co-operative federal-provincial research project under the Agricultural Rehabilitation and Development Act. The correct title of the Act of Parliament, of which ARDA is the shortened form is "An Act to provide for the Rehabilitation of Agricultural Lands and the Development of Rural Areas in Canada". It is perhaps unfortunate that the common use of the short title has encouraged an agricultural bias which was never intended. In fact one major objective of the program is to get marginal or submarginal agricultural lands out of agriculture and into alternative uses for which they have a higher capability, thereby contributing to the regional economy and the tax base of the municipality. Whether we like the words or not land planning is implied and the first step is to secure a technical capability base from which to proceed. It is this base which the Canada Land Inventory was designed to provide and it is in this context that we can discuss it.

The need for a land capability inventory has not arisen suddenly. Abandoned farms particularly in Eastern Canada, silted rivers and streams, and eroded hillsides are mute testimony to man's disregard of the inherent properties of the land on which he lives and works. The urgent necessity of such a program was pointed out by the continuing Senate of Canada Special Committee on Land Use and the Resources for Tomorrow Conference of 1961. At about the same time sufficient basic information and trained personnel were available in Canada to permit at least a first approximation of land capability for its various uses.

In 1962, terms of reference, financial, and administrative structure of the program were established in the ARDA Administration. In November of that year a national seminar representing most relevant disciplines and areas of interest recommended an inventory essentially along the lines on which it is being carried out. At about the same time the Canadian Council of Resource Ministers approved the proposal in principle and recommended that the inventory proceed on the basis of working agreements between individual provinces and the ARDA Administration. On October 3, 1963 the Government of Canada approved the undertaking.

For reasons outlined earlier the Inventory! will cover the agricultural lands and forested fringe areas of Canada which affect the income and level of employment of rural residents. Stated in another way it will cover the "settled" areas of Canada. A total of approximately 1 million square miles is involved. It is important to note that lands which have been and are likely to remain in forests will not be covered.

\footnotetext{
${ }^{1}$ Forestry Coordinator, Canada Land Inventory, Department of Forestry, Ottawa.
} 
The role of the federal government is primarily one of enabling and co-ordinating; thus the Government of Canada has agreed to finance all additional expenditures required of the provinces in the conduct of the inventory, to stimulate and direct the development of national capability systems, to provide technical assistance through the co-operation of federal research personnel, to co-ordinate the program nationally, to provide facilities for data processing and map compilation and to undertake publication of results on a national basis at a scale of 1:250,000.

The provinces, usually under the direction of an Inventory Committee, are responsible for the planning and conduct of the inventory and the preparation of capability maps. They are also responsible for the publication of results at other than the national scale.

Having outlined briefly the history and administrative structure, we now come to a consideration of what it embraces. Within the Inventory boundary lands will be classified according to their capability for agriculture, forestry, wildlife, and recreation. They will be mapped according to their present use and an assessment of the socio-economic factors relative to their present use will be carried out. In the consideration of the individual sectors, since your primary interest is in the capability for forestry, I will deal with it at greater length.

\section{1) Present Land Use}

In eastern Canada the present land use mapping is being carried out by the Geographical Branch of Canada, Department of Mines and Technical Surveys. In western Canada the provinces are responsible for this mapping. The Geography Department of the Provincial Universities in most cases are carrying out this mapping under the direction of the provincial governments. Major classes mapped are urban, that is land used for urban and associated non-agricultural uses; horticulture, which includes land used for the intensive production of vegetables and small fruits; orchards and vineyards; cropland, land used primarily for cash crops; improved pasture and forage crops; unimproved pasture and range land; woodland; swamp, marsh or bog; unproductive land.

The maps are being prepared at $1: 50,000$ or as closely as possible depending on availability of base maps.

\section{2) Soil Capability for Agriculture}

This mapping is being carried out by the federal and provincial soil survey organizations using as a base the soil survey maps and reports which had previously been prepared for much of the settled area of Canada.

Land is classified into one of seven capability classes on the basis of the nature and degree of physical limitations to use. Classes 1 to 4 include those lands which can be cultivated on a permanent basis; Classes 5 and 6 are reserved for soils which may be used for permanent pasture and the last class consists of lands which are unsuitable for agriculture.

Initial mapping is at the same scale as the soil survey maps, from 1 mile to the inch to 3 miles to the inch and the mapped units are generalized and complexed to a 1:250,000 base for publication. 


\section{3) Land Capability for Recreation}

This classification is still in the developmental stages and may change somewhat. At the moment the system comprises seven classes based on the natural capability of the land to provide recreation. The degree of attractiveness, the range of recreational activities and the number of people which might be accommodated per unit area are dominant factors. Classes 1 to 3 include lands adjoining water bodies and are suitable for water-oriented recreation. Areas containing outstanding natural attractions but not necessarily contiguous to water are in parallel but special Classes 1 or 2 . Classes 4 and 5 include those lands with recreational potential of a nonwater-oriented nature. Class 6 land has severe limitations for recreational activities and Class 7 land has an extremely limited or no natural capability for any type of recreation.

Mapping will be carried out at the approximate scale of 1:50,000 and generalized or complexed to $1: 250,000$ for publication.

\section{4) Land Capability for Wildlife}

Once again the classification system may be revised as a result of pilot projects now in progress.

Essentially the capability classification for wildlife comprises two separate classifications.

In the first, the land is rated in a 7 class system according to its ability to support the production of waterfowl. The class is determined by the inherent physical limitations to the formation and maintenance of waterfowl habitat and growth of vegetation necessary for survival and growth. Land especially adapted to serve as migration areas is recognized by a special class.

The second wildlife classification divides the land into 1 of 7 classes based on the physical limitations of the land for the production of ungulates (hoofed animals). Associated with each class is a range of numbers of deer and/or moose which the land will support as well as a minimum annual productivity estimate.

Mapping will be on a similar basis to that of recreation.

\section{5) Land Capability for Forestry}

Many of you are aware of the Canadian Land Capability Classification for Forestry but for those of you who are not I propose to outline it in a little more depth than was the case with the other sectors.

The original system was drawn up following discussions with each of the provinces early in 1964. After a series of pilot projects to test the applicability and usefulness of the preliminary system, it was further reviewed at a series of regional meetings late in 1964 and adopted in its present form at a national meeting in January, 1965. All of the provinces, Forestry Faculties of the Universities and Regional Offices of Canada Department of Forestry were represented at the national meeting.

Land is rated into 1 of 7 classes based on its inherent physical limitations to the growth of commercial forests and on its capability to produce a mean annual increment of a minimum volume of a stated species. To 
accommodate areas such as the coast forests of British Columbia in a national system, provision has been made to allow subdivision of Class 1 into subclasses on the basis of productivity.

Thus Class 1 soils will have no important limitations to growth and the productivity of the best commercial species will usually be greater than 110 cubic feet per acre per year to rotation age.

Class 2 soils may have slight limitations of available nutrients, moisture or climate. Productivity will usually be from 91 to 110 cubic feet per acre per year.

Class 3 soils may be of sufficiently coarse texture to moderately affect the supply of available moisture and nutrients or heavy textured soils with somewhat impeded internal drainage. Rooting depth may be somewhat limited or the restricted depth may adversely affect the available moisture. Productivity will usually be 71 to 90 cubic feet per acre per year.

As the limitations to growth become more severe either in intensity or of a more severe type, the capability decreases along with a productivity decrease for each class of 20 cubic feet per acre per year until Class 7 in which the limitations are of such a severe nature as to preclude the growth of commercial forests. Productivity in this class will usually be less than 10 cubic feet per acre per year.

Productivity estimates are based, whenever possible, on measurements of "normal", that is, fully stocked stands and are expressed as mean annual increment in cubic feet per acre per year to rotation age of gross merchantable volume, exclusive of thinnings, bark and branch wood.

In this paper I have made no attempt to outline the classification system in detail. Copies of the Classification System and Guidelines for its use are available from Canada Department of Forestry.

For the purpose of this meeting we can consider one symbol of one classified land unit, and thus establish the principle of classification.

$$
A_{\mathrm{w}}^{\mathrm{W}}
$$

indicates the unit is classified as capability 4, growth being limited by excessive moisture (W) and a dense soil or layers within the surface soil which limit rooting depth (D). Potential production (i.e. productivity) for white spruce will be from 51 to 70 cubic feet per acre per year to rotation age in gross merchantable volume, exclusive of thinnings, bark, and branch wood.

Admittedly the system does not treat of as much detail as many of the provinces feel they: need, particularly if it is to be used as a basis for management. Perhaps in its defence the best thing that can be said is that $I$ have seen it effectively working from the Maritimes through Quebec to British Columbia; in fact although at first glance it seems simple, in practice a high degree of experience is necessary in order to classify consistently. Thus it is probably the best we can do considering the present scarcity of trained men. 
In most provinces two maps will be produced, one at a larger scale than 1:250,000, often 1:50,000 for computer input and another at 1:250,000 for publication. It must be understood that each of the provinces is carrying out its own capability program with an anticipated completion date of 1969-70.

Partly to periodically review the forest land capability system and partly to stimulate a national approach to forest land classification, the Minister of Forestry has recently announced the formation of an Advisory Committee to be called the National Committee on Forest Land. This Committee will consist of an official delegate from each of the provinces, Forestry Faculties of each Canadian University, and the Regional offices of Canada Department of Forestry. There will be representation from the National Soil Survey of Canada Department of Agriculture, Canadian Wildlife and National Parks Services of Department of Northern Affairs and National Resources, and the Canada Land Inventory of ARDA.

The terms of reference of this Committee will undoubtedly be published in the Chronicle. I believe it will prove to be a giant stride in our efforts to promote better wild, that is non-agricultural, land management, particularly if a national approach towards the classification of the growing medium can be stimulated.

Several times reference has been made to the fact that maps will be produced at two scales, one at a scale up to 1:50,000 depending on base map availability and another at $1: 250,000$ for publication. A conservative estimate of the number of maps resulting from this program is approximately 10,000 . Obviously one critical phase of the inventory is the development of a system which will enable rapid area calculation, rapid comparison within and between capabilities for a specified region and a storage and recovery system which will allow quick recall of required information.

Through contracts ARDA is developing a computer system in which map lines will be recorded on magnetic tape in a numerical form by means of an automatic scanning device. All pertinent information for any land unit, including capabilities, present use, economic factors and population characteristics can then be placed on the tape along with the land unit. When perfected this will allow rapid area calculation, rapid multiple comparisons and the maps may be printed out at any required scale. With projected improvement in computer techniques it is quite possible that before the Inventory is complete, corrections, additions or deletions can be effected with direct map projections from the tape.

No discussion of the Inventory would be complete without considering the most important aspect, that is, what are its uses. Obviously these will have to be a major consideration in the design. A classification in which motherhood is good and $\sin$ is bad is of little value if the first case for classification is one in which motherhood was achieved in $\sin$.

The Canada Land Inventory has been designed as a basis for land planning and not primarily for land management. In general it will not be sufficiently detailed nor at a large enough scale to provide a base for management. Since land planning is within the jurisdiction of the provinces, its maximum use will be by the provinces. However, it is certainly in the national interest 
to encourage good land use, and the support of a physical basis to enable this is easily rationalized.

Perhaps the greatest value of the study, and the one in which ARDA's primary interest lies, is that it will provide a logical base for land consolidation for specific purpose, land purchase for alternative uses, and land development for the use for which it is most suited. Regional economies will only be improved if the land resource is properly utilized.

While, as mentioned earlier, it is not intended as a base for management it will indicate on which lands intensive management with necessary long term investments should be carried out. Thus its value as a tool for management should not be underrated.

Finally, without dwelling on details, I think it may be stated that, for the first time in Canada, a technical base will exist for enlightened land use planning. In a democratic country we often hesitate to pursue the implications of land use planning because it smacks of a regimentation which is foreign to our way of life. It seems to me that the alternative, which we have been practising, has been shown to be unacceptable. It will be a long step in the right direction if we at least provide a base showing the capability of the land for its various uses. This I believe the Canada Land Inventory will provide. 